\title{
WORKSHOP DAN SOSIALISASI PENGGUNAAN ALAT PRAKTIKUM IPA SEKOLAH DASAR DI SDN PULO PANJANG
}

\author{
Diana Ayu Rostikawati ${ }^{*}$, Dedy Khaerudin ${ }^{2}$, Elga Sandi Kiawati ${ }^{3}$ \\ 1,2,3 Universitas Bina Bangsa \\ dianaayu.rostikawati@binabangsa.ac.id
}

\begin{abstract}
ABSTRAK
Pembelajaran IPA di SD sebaiknya lebih menekankan pada proses melalui kegiatan praktikum, saat ini pembelajaran guru dikelas masih sebatas penyampaian teori dan jarang mengajak siswa untuk melakukan pratikum karena keterbatasan alat praktikum yang dimiliki sekolah. Berdasarkan hasil observasi di lapangan, hal ini juga dialami oleh guru IPA di SDN Pulo Panjang. Berdasarkan permasalahan tersebut, maka dilaksanakan kegiatan pengabdian kepada masyarakat berupa workshop dan sosialisasi penggunaan alat praktikum IPA, kegiatan ini terdiri dari dua tahapan yaitu tahapan persiapan dan pelaksanaan. Pada tahap persiapan dihasilkan alat-alat peraga sederhana untuk praktikum IPA, kemudian alat-alat peraga ini di demonstrasikan pada tahap pelaksanaan. Di tahap pelaksanaan pemateri memaparkan dan mendemontrasikan beberapa praktikum yang berkaitan dengan materi kelistrikan \& kemagnetan dan materi tekanan. Ada beberapa hal yang diperoleh oleh peserta setelah diadakannya workshop ini yaitu 1) Knowledge (Pengetahuan), setelah workshop terlihat bahwa peserta mendapatkan ilmu pengetahuan baru tentang pelaksanaan praktikum IPA SD, 2) Kemampuan, peserta terlihat telah memiliki keterampilan untuk melakukan kegiatan praktikum IPA SD, dan 3) Produk, setelah workshop dilaksanakan, alat peraga praktikum IPA akan diberikan/hibahkan ke pihak sekolah, alat peraga IPA yang diberikan dilengkapi dengan panduan/modul.

Kata kunci : workshop, alat praktikum IPA, sekolah dasar
\end{abstract}

\section{ABSTRACT}

Science learning in elementary schools should more emphasis on process through practicum activities, currently science learning in the class is still limited to delivering theory and rarely invites students to do practicals because of the limitations of practicum tools owned by the school. Based on observations, this is also experienced by science teachers at SDN Pulo Panjang. Based on these problems, community service activities were carried out in the form of workshops and socialization of use science practicum tools, this activity consisted of two steps, e.g. preparation and implementation. At preparation step, simple practicum tools are produced for science practicum, then these practicum tools are demonstrated at implementation step. At implementation step, the speaker explained and demonstrated several practicums related to electricity \& magnetism and pressure materials. There are several things that participants gained after holding this workshop, e.g. 1) Knowledge, after the workshop it was seen that participants got new knowledge about implementation of elementary science practicum, 2) Skill, participants seemed to have tskills to carry out elementary science practicum activities, and 3) Products, after the workshop, science practicum tools will be given to the school, science practicum tools provided are equipped with guides/modules.

Keywords: workshop, science practicum tools, elementary school 
Prosiding The 1st National Conference on Applied Business, Education, \& Technology (NCABET)"

Unversitas Bina Bangsa 2021

DOI Article : 10.46306/ncabet.v1il.33

\section{PENDAHULUAN}

Ilmu Pengetahuan Alam (IPA) berkaitan dengan cara mencari tahu (inquiry) tentang alam secara sistematis, sehingga IPA bukan hanya sebagai penguasaan kumpulan pengetahuan yang berupa fakta-fakta, konsep-konsep atau prinsip-prinsip saja, tetapi juga merupakan suatu proses penemuan. (Depdiknas, 2006). Adapun pembelajaran IPA di SD seyogyanya lebih menekankan pada proses, dimana siswa aktif selama pembelajaran untuk membangun pengetahuannya melalui serangkaian kegiatan agar pembelajaran bermakna bagi siswa. Salah satu cara untuk memahami sains adalah dengan melakukan praktikum.

Karakteristik pembelajaran IPA lebih menekankan pada pendekatan ilmiah (scientific approach). Pembelajaran menggunakan pendekatan ilmiah (scientific approach) yang menekankan proses dan produk sulit dilakukan tanpa dukungan dari ketersediaan alat, bahan praktikum, dan bahan ajar yang lain, sehingga pembelajaran IPA yang pada hakikatnya dipelajari melalui kerja ilmiah memerlukan kegiatan praktikum di laboratorium (Novianti, N.R, 2011).

Ada empat alasan mengenai pentingnya kegiatan laboratorium (praktikum) menurut Woolnough \& Allsop (dalam Rustaman, dkk, 2003) yaitu : 1) Praktikum membangkitkan motivasi belajar IPA. 2) Praktikum mengembangkan keterampilan dasar melakukan eksperimen. 3) Praktikum menjadi wahana belajar pendekatan ilmiah. 4) Praktikum menunjang materi pelajaran.

Dewasa ini secara umum pembelajaran guru dikelas masih sebatas penyampaian teori dan jarang mengajak siswa untuk melakukan pratikum karena keterbatasan alat praktikum yang dimiliki sekolah. Berdasarkan hasil pengamatan di lapangan, hal ini juga dialami oleh para guru IPA di SD Pulau Panjang, Kabupaten Serang. Sarana dan prasarana seperti fasilitas, alat peraga dan bahan praktikum IPA masih minim, jika ada jumlahnya sangat terbatas dibandingkan dengan jumlah peserta didik.

Berdasarkan informasi tersebut maka untuk mewujudkan peran penting praktikum dalam pembelajaran IPA, maka upaya pengembangan alat peraga praktikum IPA dan pelatihannya pada guru IPA di SD sangat diperlukan. Sehingga guru di sekolah mitra memiliki keterampilan dalam menggunakan alat peraga IPA. Alat peraga praktikum IPA adalah alat-alat peraga untuk Ilmu Pengetahuan Alam (IPA), berupa seperangkat peralatan IPA yang dikembangkan untuk membantu pembelajaran (Pujani, N.M \& Rapi, 2012). Program pengabdian ini bertujuan untuk meningkatkan keterampilan guru menggunakan alat peraga pembelajaran IPA dan mengenalkan alat peraga yang mudah dibuat serta dapat digunakan 
Prosiding The 1st National Conference on Applied Business, Education, \& Technology (NCABET)",

Unversitas Bina Bangsa 2021

DOI Article : 10.46306/ncabet.v1i1.33

dalam pembelajaran IPA dengan menyenangkan. Bekal keterampilan serta produk alat peraga yang dihasilkan, diharapkan dapat digunakan dan disempurnakan secara berkelanjutan

\section{METODE PELAKSANAAN}

Pelaksanaan kegiatan pengabdian pada masyarakat (PKM) ini terbagi dalam beberapa tahapan, yaitu tahap persiapan dan tahap pelaksanaan, tahap persiapan meliputi pembuatan alat peraga sederhana untuk materi kelistrikan dan kemagnetan serta alat peraga materi tekanan (permainan labirin Pascal), pada tahapan ini juga dilakukan penyusunan modul/panduan untuk beberapa praktikum yang dapat dilakukan menggunakan alat peraga yang telah dipersiapkan sebelumnya. Tahap selanjutnya adalah pelaksanaan PKM berupa workshop dan sosialisasi penggunaan alat praktikum IPA serta pemberian evaluasi berupa umpan balik dari peserta terkait tanggapan mereka terhadap materi yang telah diberikan. Penjelasan lengkap terkait setiap tahapan yang dilaksanakan pada PKM sebagai berikut :

1. Tahap Persiapan (pembuatan alat peraga sederhana)

Pembuatan alat peraga dimulai dengan mengumpulkan semua alat dan bahan yang akan digunakan. Untuk alat peraga materi kelistrikan dan kemagnetan, alat dan bahan yang digunakan adalah papan rangkaian acrylic, kabel penghubung, kabel penjepit buaya, baterai, lampu 1,5 V, sakelar, peniti, batang tembaga, paku, magnet, pensil, pulpen, penghapus, kertas, uang logam, dan sendok/garpu. Sedangkan alat peraga permainan labirin pascal membutuhkan alat dan bahan seperti, papan polycarbonate, suntikan mainan, selang kecil, lem tembak, gunting/cutter, pensil, air dan kelereng.

2. Tahap Pelaksanaan (workshop dan sosialisasi penggunaan alat praktikum IPA) Pelaksanaan workshop dan sosialisasi penggunaan alat praktikum dimulai dengan pemaparan materi dan demonstrasi beberapa praktikum IPA dengan menggunakan alat-alat peraga yang telah dipersiapkan sebelumnya. Kemudian acara dilanjutkan dengan uji coba/praktek alat-alat peraga secara langsung oleh peserta workshop, acara terakhir yaitu hibah/ pemberian alat peraga yang dilakukan secara simbolis oleh pemateri kepada pihak sekolah. Workshop dilakukan pada hari Senin, 16 Agustus 2021 yang dihadiri oleh 7 orang guru SDN Pulo Panjang. Acara berlangsung mulai jam 10.00 pagi hingga 12.00 WIB di SDN Pulo Panjang, Kabupaten Serang, Provinsi Banten.

\section{HASIL DAN PEMBAHASAN}

1. Alat Peraga Praktikum IPA Sederhana

Hasil dari tahap persiapan untuk kegiatan PKM ini adalah alat peraga praktikum IPA untuk materi kelistrikan dan kemagnetan serta alat peraga untuk materi tekanan (permainan labirin 
Prosiding The 1st National Conference on Applied Business, Education, \& Technology (NCABET)", Unversitas Bina Bangsa 2021

DOI Article : 10.46306/ncabet.v1i1.33

Pascal). Pada tahapan ini dihasilkan pula modul/panduan untuk beberapa praktikum yang dapat dilakukan menggunakan alat peraga tersebut. Berikut gambaran alat peraga danpanduannya.
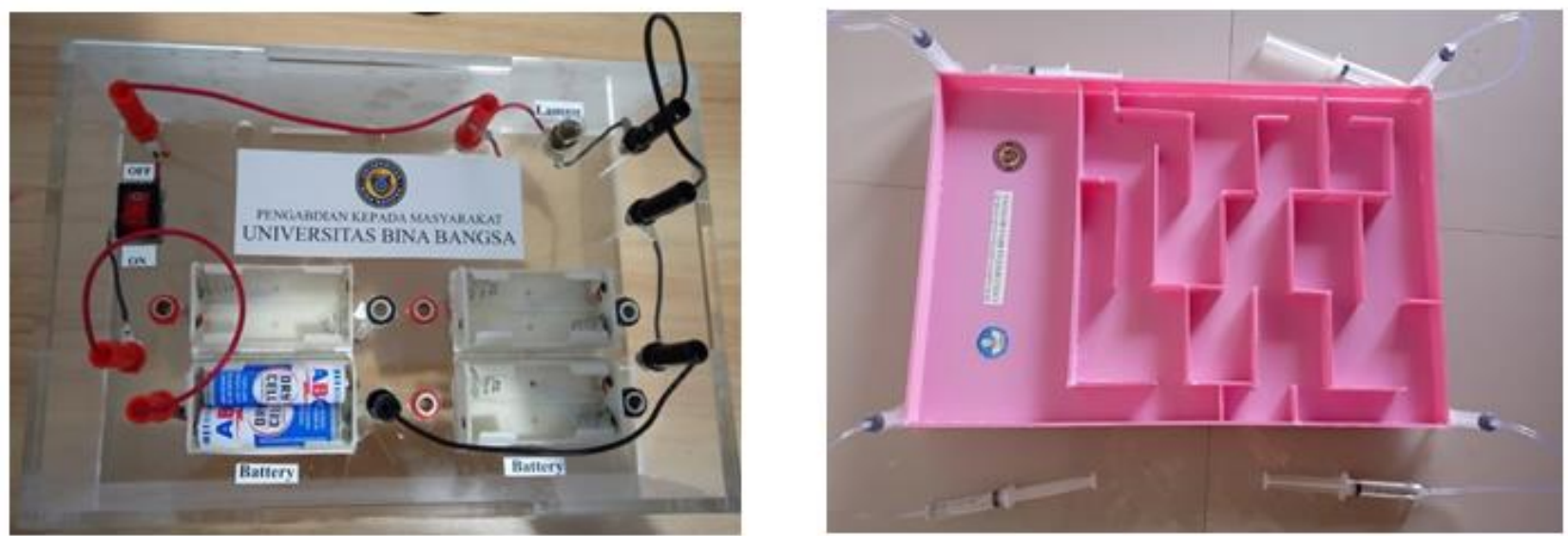

Gambar 1. Alat Peraga Praktikum IPA yang Dihasilkan Pada Tahap Persiapan

2. Pelaksanaan workshop dan sosialisasi penggunaan alat praktikum IPA
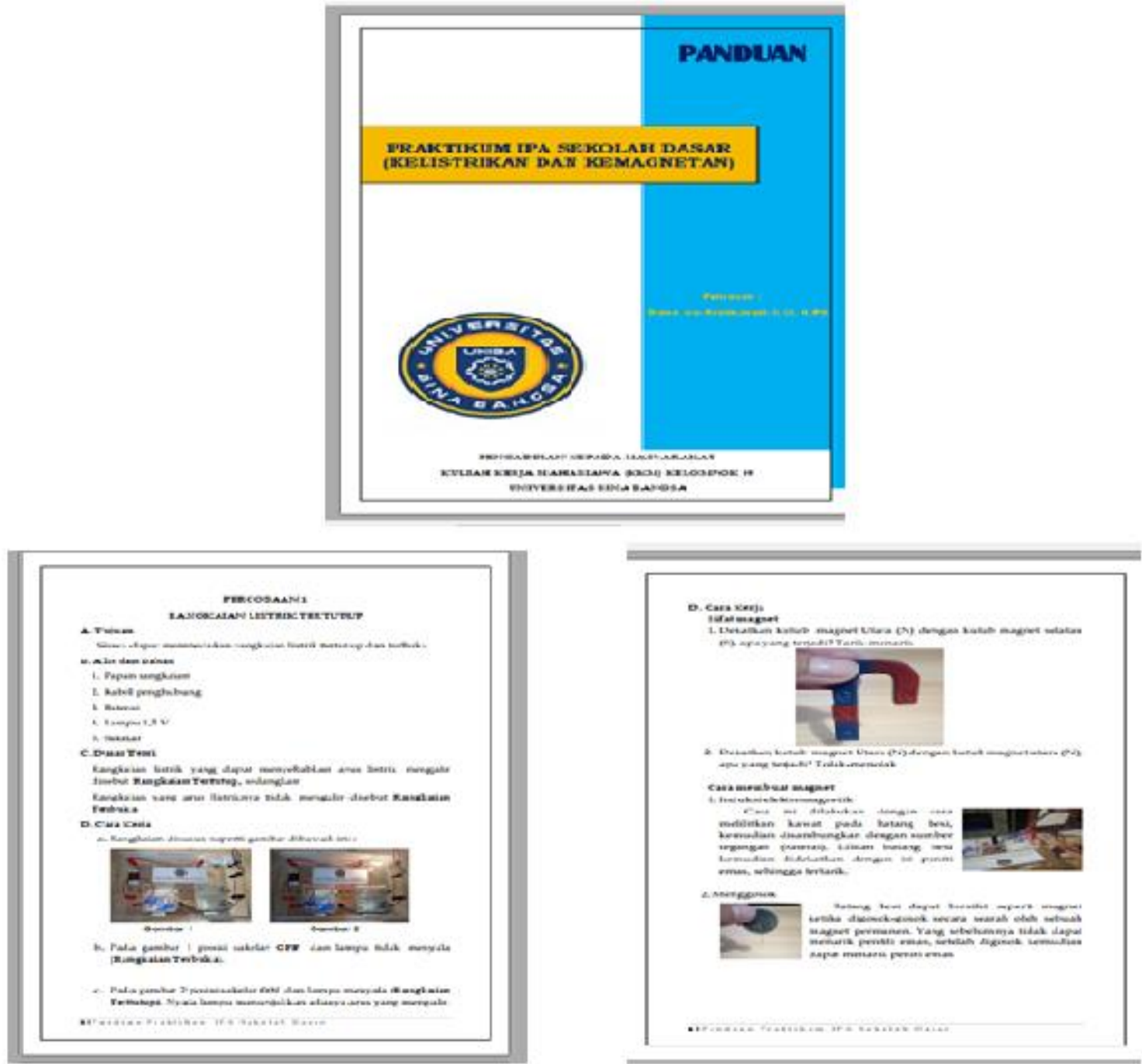

Gambar 2. Tampilan Panduan/Modul Praktikum IPA 
Prosiding The 1st National Conference on Applied Business, Education, \& Technology (NCABET)"

Unversitas Bina Bangsa 2021

DOI Article : 10.46306/ncabet.v1i1.33

Pelaksanaan workshop dan sosialisasi penggunaan alat praktikum IPA di Sekolah Dasar, diawali dengan sambutan dari kepala sekolah SDN Pulo Panjang, kemudian dilanjutkan dengan pemaparan materi dan demontrasi alat peraga praktikum IPA oleh pemateri. Ada empat materi prakikum sederhana yang dipresentasikan yaitu Rangkaian Listrik Tertutup \& Terbuka, Penghantar Listrik (Konduktor \& Isolator), Sifat Magnet \& Magnet Buatan, dan Permainan Labirin Pascal. Setelah memaparkan dan mendemontrasikan praktikum-praktikum sederhana tersebut, para peserta kemudian diberi kesempatan untuk uji coba/mempraktekan langsung penggunaan alat peraga yang telah dipersiapkan. Sebelum acara ditutup, dilakukan prosesi hibah/ pemberian alat peraga yang dilakukan secara simbolis oleh pemateri kepada pihak sekolah tempat workshop diselenggarakan. Berikut beberapa gambaran materi praktikum sederhana yang dipresentasikan.
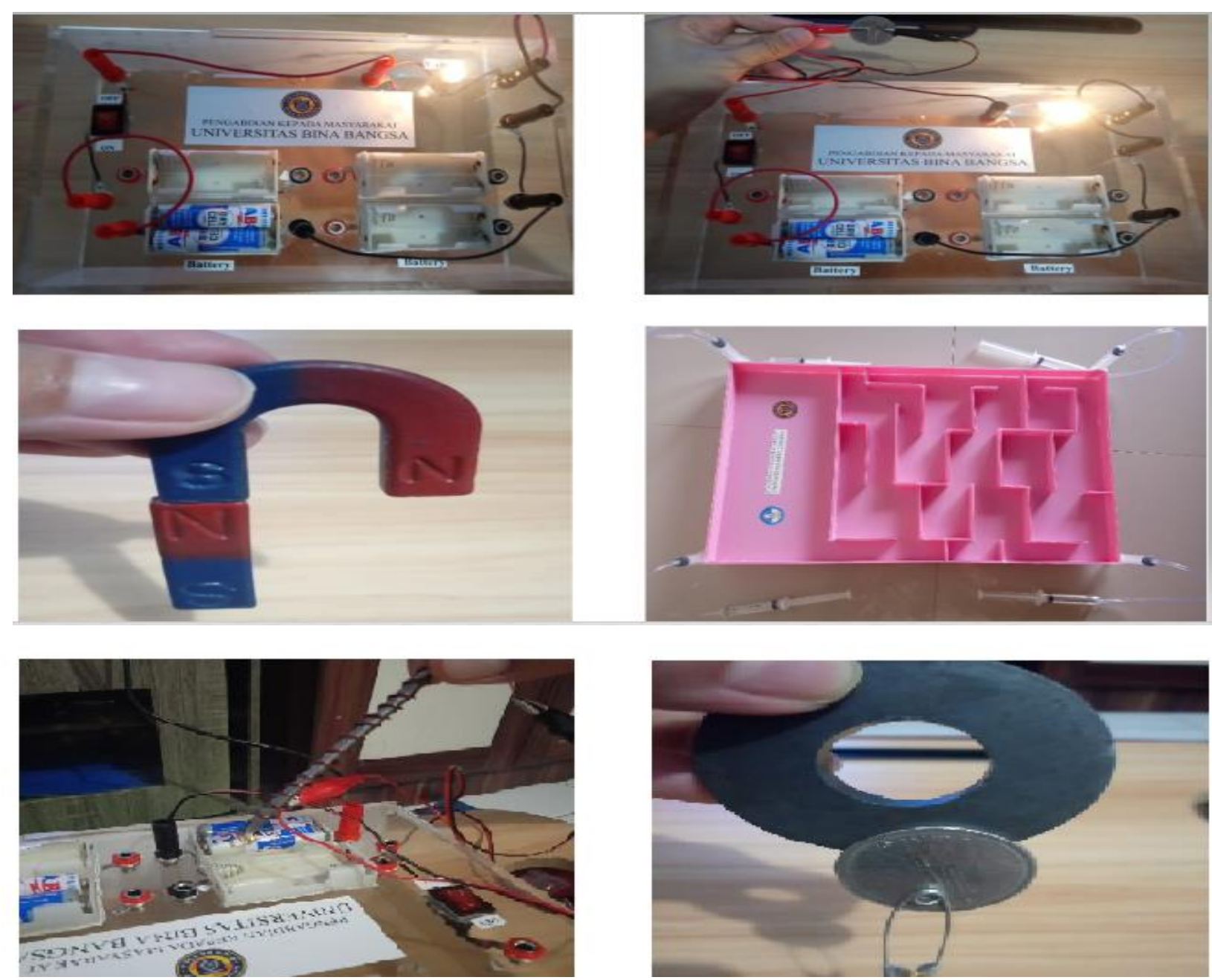

Gambar 3. Praktikum IPA Sederhana Terkait Materi Kelistrikan \& Kemagnetan dan Tekanan 
Prosiding The 1st National Conference on Applied Business, Education, \& Technology (NCABET)", Unversitas Bina Bangsa 2021

DOI Article : 10.46306/ncabet.v1i1.33

Adapun beberapa dokumentasi pelaksanaan workshop dapat dilihat pada gambar berikut.
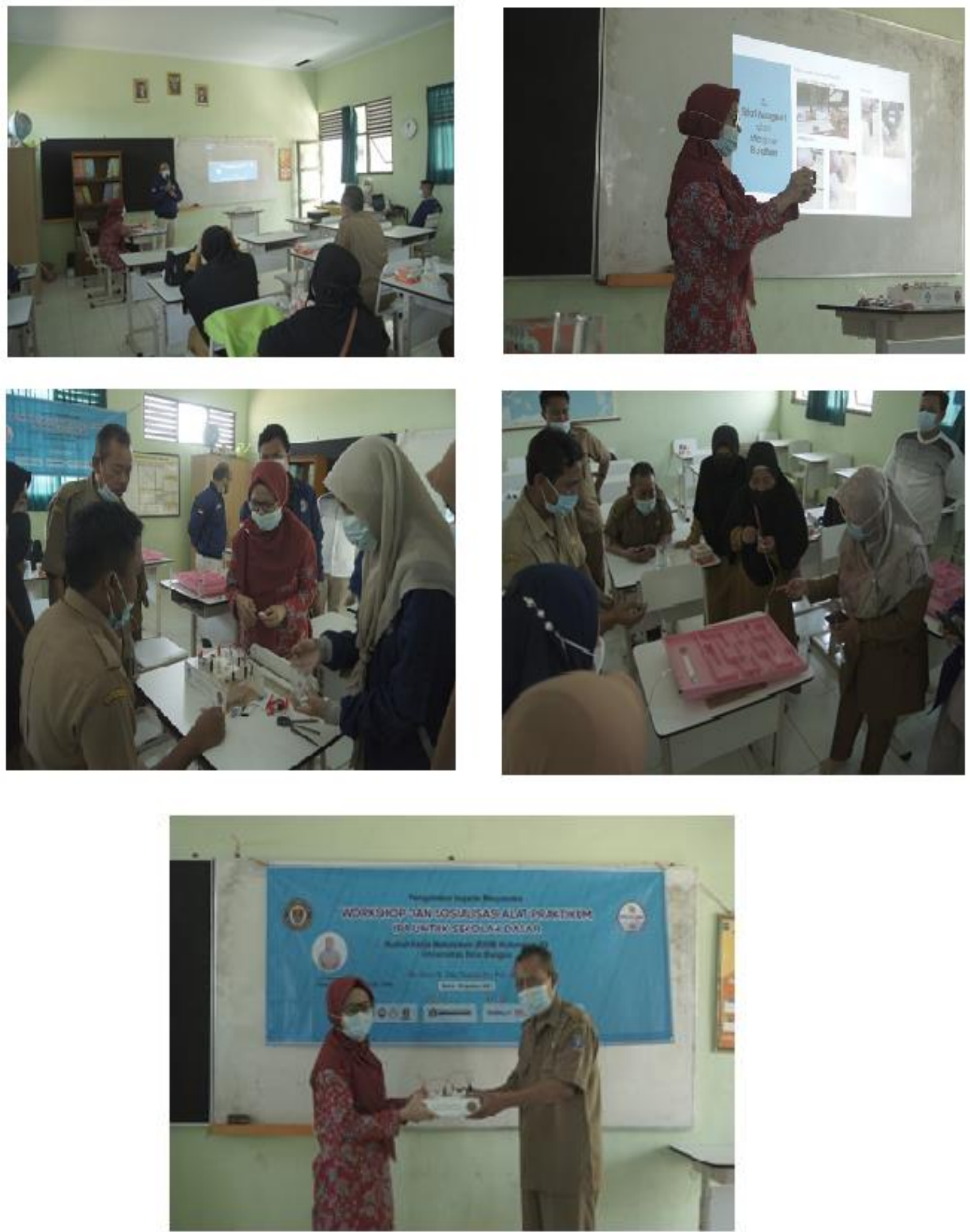

Gambar 4. Dokumentasi Pelaksanaan Workshop dan Sosialisasi Alat Praktikum IPA di SD 
Prosiding The 1st National Conference on Applied Business, Education, \& Technology (NCABET)"

Unversitas Bina Bangsa 2021

DOI Article : 10.46306/ncabet.v1i1.33

Setelah kegiatan workshop praktikum dilaksanakan, diharapkan akan memberikan dampak yang baik bagi para peserta. Adapun yang diperoleh oleh peserta setelah diadakannya workshop ini diantaranya, yaitu 1. Knowledge (Pengetahuan), berdasarkan tanggapan dari masing-masing peserta terkait pelaksanan workshop, diperoleh informasi bahwa guru merasa senang dan mendapat banyak manfaaat dari kegiatan workshop praktikum ini. Peserta mendapatkan ilmu pengetahuan baru tentang pelaksanaan beberapa praktikum IPA di sekolah dasar yang kelak dapat dipraktikkan di kelas bersama dengan siswa. Berdasarkan wawancara dengan beberapa orang peserta, mereka merasa praktikum yang dilaksanakan lebih menekankan pada pemahaman konsep dan langsung berhubungan dengan materi pelajaran di kelas. 2. Skill (Kemampuan), berdasarkan observasi tim pelaksana PKM selama berlangsungnya workshop,peserta terlihat telah memiliki keterampilan untuk melakukan kegiatan praktikum IPA SD. 3. Produk, setelah workshop dilaksanakan, alat peraga praktikum IPA akan diberikan/hibahkan ke pihak sekolah, alat peraga IPA yang diberikan dilengkapi dengan panduan/modul.

Selanjutnya berdasarkan tanggapan yang diperoleh dari peserta diperoleh informasi bahwa para peserta merasa senang dengan workshop praktikum IPA ini karena menambah ilmu dan dirasa sangat bermanfaat dalam kegiatan pembelajaran. Peserta juga mengharapakan ada kelanjutan dari kegiatan ini. Peserta mendapatkan pengalaman baru melakukan percobaan IPA secara sederhana tetapi menyenangkan karena proses percobaanya dilakukan dengan menggunakan alat peraga yang berbentuk permainan. Kegiatan ini pun dapat dikatakan mampu memotivasi, meningkatkan dan memperbaharui pengetahuan para peserta. Hasil ini sejalan dengan hasil yang diperoleh beberapa PKM yang telah dilaksanakan sebelumnya oleh (Juartina, dkk, 2019, Sari \& Ritonga, 2018, dan Putri, dkk, 2019), yang menunjukkan bahwa kegiatan PKM yang berkaitan dengan pelatihan/pendampingan/ workshop terkait alat praktikum IPA baik di sekolah dasar maupun menengah sangat membantu peserta untuk meningkatkan pengetahuan dan kemampuannya dalam hal praktikum. Melalui kegiatan PKM seperti ini, kita ketahui pula tidak ada yang sulit dalam menyiapkan praktikum IPA, karena dapat dibuat dengan sangat mudah dengan memanfaatkan fasilitas atau alat disekitar lingkungan sekolah.

\section{KESIMPULAN DAN SARAN}

Berdasarkan kegiatan pengabdian masyarakat yang telah dilakukan oleh penulis dibantu oleh KKM kelompok 39 Universitas Bina Bangsa ini dapat diambil kesimpulan sebagai berikut: 1) Dihasilkan alat-alat peraga sederhana untuk praktikum IPA dilengkapi dengan 
Prosiding The 1st National Conference on Applied Business, Education, \& Technology (NCABET)"

Unversitas Bina Bangsa 2021

DOI Article : 10.46306/ncabet.v1i1.33

panduan/modul terkait praktikum yang bisa dilakukan menggunakan alat peraga yang dihasilkan.

2) Kegiatan workshop praktikum IPA SD yang telah dilakukan memberikan manfaat dalam hal mengatasi permasalahan peserta yaitu dapat meningkatkan pengetahuan dan kemampuan guru dalam melakukan praktikum IPA di SD, selain itu alat peraga praktikum IPA yang dipresentasikan pada akhirnya diberikan pada pihak sekolah sehingga guru dapat menggunakan alat peraga tersebut dalam proses pembelajaran. Selanjunya berdasarkan evaluasi kegiatan dari hasil tanggapan para peserta, diperoleh informasi yaitu kegiatan ini mampu memotivasi, meningkatkan dan memperbaharui pengetahuan para peserta, peserta juga mendapatkan pengalaman baru melakukan percobaan IPA secara sederhana tetapi menyenangkan. Adapun saran yang diberikan peserta adalah agar kegiatan PKM seperti ini dapat dilakukan secara berkelanjutan.

\section{UCAPAN TERIMAKASIH}

Ucapan terima kasih kepada Rektor dan LPPM Universitas Bina Bangsa serta kelompok KKM 39 yang telah memberikan kesempatan dan membantu dalam persiapan dan pelaksanaan kegiatan PKM ini. Selanjutnya terima kasih kepada Kepala SDN Pulo Panjang dan seluruh guru SDN Pulo Panjang sebagai peserta kegiatan workshop yang dengan sukarela dan antusiasme yang tinggi menyempatkan waktu untuk datang dan mengikuti kegiatan sampai selesai.

\section{DAFTAR PUSTAKA}

Depdiknas. 2006. Badan Nasional Standar Pendidikan. Jakarta: Depdiknas.

Juniartina, P.P, Devi, N.L.P.L, Dewi, N.P.S.R. 2019. Pembuatan Alat Peraga IPA SMP Di Kecamatan Banjar. Prosiding SENADIMAS Ke-4. ISBN 987-623-7482-00-0.

Novianti, N.R. 2011. Kontribusi Pengelolaan Laboratorium dan Motivasi Belajar Siswa Tehadap

Efektifitas Proses Pembelajaran (Penelitian pada SMP Negeri dan Swasta di Kabupaten Kuningan Provinsi JawaBarat). Jurnal.Upi.Edu/File/15. Edisi Khusus No. 1, Agustus 2011. ISSN 1412-565X

Pujani, N.M., dan Rapi N. K. 2012. Pelatihan Praktikum IPBA Bagi Guru SMP/SMA di Kota Singaraja Menuju Olimpiade Astronomi. Jurnal Pengabdian kepada Masyarakat Widya Laksana. ISSN: 1410-4369, Edisi Juli 2012. Hal.119-130.

Rustaman, N., Dirdjosoemarto, N.Y., Yudianto, S.A., Achmad, Y., Subekti, R., Rochintaniawati, D., Nurjhani, M. 2003. Strategi Belajar Mengajar Biologi. Jurusan Pendidikan Biologi FPMIPA UPI. Bandung. 
Prosiding The 1st National Conference on Applied Business, Education, \& Technology (NCABET)"

Unversitas Bina Bangsa 2021

DOI Article : 10.46306/ncabet.v1i1.33

Sari, P.M., Ritonga, R.F. 2018. Pelatihan Praktikum IPA Bagi Guru-Guru Di SDN Makasar 08 dan SDN Makasar 09 Pagi Jakarta Timur. Prosiding Kolokium Doktor dan Seminar Hasil Penelitian Hibah. https://doi.org/ 10.22236/psd/11306-31180. Volume 1, Desember 2018 .

Putri, N.P., Sucahyo, I., Suprapto, N., Anggaryani, M. 2019. Pendampingan Pembuatan Alat Peraga Sederhana Elektrokskop dan Konversi Energi Bagi Guru IPA SMP Kota Mojokerto. SEMINAR NASIONAL FISIKA (SNF) 2019. Jurusan Fisika FMIPA UNESA. 